\title{
Correction to: Clinical and radiation dose-volume factors related to pneumonitis after treatment with radiation and durvalumab in locally advanced non-small cell lung cancer
}

\author{
Hiroto Inoue ${ }^{1} \cdot$ Akira Ono $^{1} \cdot$ Takanori Kawabata $^{2} \cdot$ Nobuaki Mamesaya $^{1} \cdot$ Takahisa Kawamura $^{1} \cdot$ Haruki Kobayashi $^{1}$. \\ Shota Omori ${ }^{1} \cdot$ Kazushige Wakuda $^{1}$ - Hirotsugu Kenmotsu ${ }^{1} \cdot$ Tateaki Naito $^{1} \cdot$ Haruyasu Murakami $^{1} \cdot$ Kazuaki Yasui $^{3}$. \\ Hirofumi Ogawa ${ }^{3} \cdot$ Tsuyoshi Onoe $^{3} \cdot$ Masahiro Endo $^{4} \cdot$ Hideyuki Harada $^{3} \cdot$ Toshiaki Takahashi $^{1}$
}

Published online: 26 June 2020

(C) Springer Science+Business Media, LLC, part of Springer Nature 2020

\section{Correction to: Invest New Drugs} https://doi.org/10.1007/s10637-020-00917-2

Corrections are needed to the original version of this article. In Table 2, the "Odds ratio" of the variables "Lower lobe vs. Upper lobe" and " $\geq 26$ vs. $<26$ " should be 2.250 instead of 2250 and 2.250 instead of 2.25 .

The authors apologize for the corrections and further state that the changes does not affect the overall outcome of the study. The corrected Table 2 is shown below:
Table 2 Univariate analysis of variables associated with Gr 2 pneumonitis

\begin{tabular}{llll}
\hline Variables & & Odds ratio & $p$ value \\
\hline Age (years) & $\geq 70$ vs. $<70$ & 2.500 & 0.237 \\
Sex & Male vs. Female & 0.333 & 0.163 \\
Pathological type & Adeno vs. Squamous & 0.486 & 0.343 \\
Location & Lower lobe vs. Upper lobe & 2.250 & 0.305 \\
Smoking history & Yes vs. No & 0.257 & 0.148 \\
Baseline pneumonitis & Yes vs. No & 0.500 & 0.470 \\
Radiation & Proton beam vs. X-ray & 3.889 & 0.148 \\
Facility & Our institution vs. others & 0.524 & 0.517 \\
V20 & $\geq 26$ vs. <26 & 2.250 & 0.305 \\
V20 (continuous) & & 1.047 & 0.303 \\
\hline
\end{tabular}

Publisher's note Springer Nature remains neutral with regard to jurisdictional claims in published maps and institutional affiliations.

The online version of the original article can be found at https://doi.org/ 10.1007/s10637-020-00917-2

Akira Ono

a.ono@scchr.jp

1 Division of Thoracic Oncology, Shizuoka Cancer Center, 1007

Shimonagakubo, Nagaizumi, Sunto-gun, Shizuoka 411-8777, Japan

2 Clinical Research Center, Shizuoka Cancer Center, Shizuoka, Japan

3 Division of Radiation Oncology, Shizuoka Cancer Center,

Shizuoka, Japan

4 Division of Diagnostic Radiology, Shizuoka Cancer Center,

Shizuoka, Japan 